\title{
Features of Golf-Related Shoulder Pain in Korean Amateur Golfers
}

\author{
Chang Hwa Lee, $\mathrm{MD}^{1}$, Jin Young Hong, $\mathrm{MD}^{2}$, Po Song Jeon, $\mathrm{MD}^{1}$, Ki Hun Hwang, $\mathrm{MD}^{1}$, \\ Won Sik Moon, $\mathrm{MD}^{1}$, Yong Hyun Han, $\mathrm{MD}^{1}$, Ho Joong Jeong, $\mathrm{MD}^{3}$
}

\begin{abstract}
${ }^{1}$ Department of Rehabilitation Medicine, Dong-Eui Medical Center, Busan; ${ }^{2}$ Department of Rehabilitation Medicine, Walk Rehabilitation Hospital, Busan; ${ }^{3}$ Department of Physical Medicine and Rehabilitation, Kosin University Gospel Hospital, Kosin University College of Medicine, Busan, Korea
\end{abstract}

Objective To investigate the causes and characteristics of golf-related shoulder injuries in Korean amateur golfers. Methods Golf-related surveys were administered to, and ultrasonography were conducted on, 77 Korean amateur golfers with golf-related shoulder pain. The correlation between the golf-related surveys and ultrasonographic findings were investigated.

Results The non-dominant shoulder is more likely to have golf-related pain and abnormal findings on ultrasonography than is the dominant shoulder. Supraspinatus muscle tear was the most frequent type of injury on ultrasonography, followed by subscapularis muscle tear. Investigation of the participants' golf-related habits revealed that only the amount of time spent practicing golf was correlated with supraspinatus muscle tear. No correlation was observed between the most painful swing phases and abnormal ultrasonographic findings. Participants who had not previously visited clinics were more likely to present with abnormal ultrasonographic findings, and many of the participants complained of additional upper limb pain.

Conclusion Golf-related shoulder injuries and pain are most likely to be observed in the non-dominant shoulder. The supraspinatus muscle was the most susceptible muscle to damage. A correlation was observed between time spent practicing golf and supraspinatus muscle tear.

Keywords Golf, Shoulder pain, Ultrasonography

\section{INTRODUCTION}

According to the Korean Gold Research Report in 2014, there are an estimated 5,310,000 Korean golfers. The size of this population ranks fifth worldwide and has seen a rapid increase recently. With such a large number of people playing golf, cases of golf-related pain are also increasing. Both professional and amateur golfers are

Received August 22, 2016; Accepted September 20, 2016

Corresponding author: Ho Joong Jeong

Department of Physical Medicine and Rehabilitation, Kosin University Gospel Hospital, Kosin University College of Medicine, 262 Gamcheon-ro, Seogu, Busan 49267, Korea. Tel: +82-51-990-6262, Fax: +82-51-241-2019, E-mail: jhjpmr@naver.com

ORCID: Chang Hwa Lee (http://orcid.org/0000-0003-4206-6297); Jin Young Hong (http://orcid.org/0000-0001-6941-4832); Po Song Jeon (http://orcid. org/0000-0001-7288-2135); Ki Hun Hwang (http://orcid.org/0000-0002-8041-4363); Won Sik Moon (http://orcid.org/0000-0001-9890-5913); Yong Hyun Han (http://orcid.org/0000-0002-8960-186X); Ho Joong Jeong (http://orcid.org/0000-0002-0607-2799).

@ This is an open-access article distributed under the terms of the Creative Commons Attribution Non-Commercial License (http://creativecommons.org/ licenses/by-nc/4.0) which permits unrestricted noncommercial use, distribution, and reproduction in any medium, provided the original work is properly cited. Copyright $\odot 2017$ by Korean Academy of Rehabilitation Medicine 
reporting large numbers of golf-related injuries. The estimated prevalence of golf-related injuries ranges from as low as $25 \%$ to as high as $62 \%[1,2]$. The most commonly injured body part in amateur golfers is the upper limbs, followed by the vertebrae and then the lower limbs [2,3]. Although different studies suggest different results, the shoulder is a commonly injured body part in golfers, after the elbow and the wrist. The most common cause of shoulder injury, including rotator cuff tear, is known to be impingement syndrome [4]. A previous study [5] reported that of 412 patients with golf-related injuries, shoulder injury was observed in 85 patients, 79 of whom had rotator cuff tears or impingement. Although shoulder injuries comprise a large portion of golf-related injuries, there are few studies on golf-related shoulder injuries, whereas golf-related elbow, wrist, and back pain are being actively researched. In particular, there are few studies on golfrelated shoulder injuries in amateur golfers, who account for most of the golfing population in Korea.

Since its introduction as a method for assessing rotator cuff tears, ultrasound has been used as an important diagnostic tool. Ultrasound, a non-invasive procedure that requires a short examination time, is relatively inexpensive and does not produce radiation [6]. Because of many improvements in this technology, ultrasound currently has a high sensitivity and specificity, comparable to those of magnetic resonance imaging. Ultrasound allows for dynamic examinations and simultaneous comparison of both sides of the body, making it a highly valuable diagnostic tool [7].

In this study, golf-related surveys were administered to, and ultrasounds were conducted on, amateur golfers with golf-related shoulder pain to investigate the causes and characteristics of shoulder injuries.

\section{MATERIALS AND METHODS}

\section{Subjects}

The subjects of this study were amateur golfers with golf-related shoulder pain who were recruited by a recruitment notice between December 1, 2015 and May 31, 2016. The study was conducted at Walk Rehabilitation Hospital. Participants with golf experience of 3 months or less, those whose cause of injury was indeterminate, those who were 60 years of age or older, those whose rotator cuff damage could have been caused by degenera- tive changes [8], those with preexisting conditions that could cause shoulder abnormalities, those with a history of shoulder surgery, and those with shoulder pain that started before their introduction to golf were excluded. A total of 77 participants were selected for this study. The experimental procedure and the purpose of the study were explained to the participants before beginning the study. Confidentiality was guaranteed and informed consent was obtained from all participants before the experiment. Approval from the Korean National Institute for Bioethics Policy was obtained before conducting the experiment.

\section{Methods}

This is a prospective study. The participants' ages, location of shoulder pain, and golf habits, including experience, average number of golf practices per week, average time spent practicing golf per week, most painful swing phase, and additional upper limb pain location were investigated with surveys.

Swing phase was divided into 3 phases: address and back swing, forward swing and impact, and follow-through. When the swing direction was from right to left, the right shoulder was labeled as the dominant shoulder, the left shoulder was labeled as the non-dominant shoulder, and the swing direction was classified as a right swing.

A single rehabilitation medicine specialist without previous knowledge of the patients conducted the ultrasound examinations. Samsung WS80A ultrasound equipment (Samsung Medison, Seoul, Korea) and linear probes with a frequency range of 7-13 $\mathrm{MHz}$ were used. The participants wore shoulder-revealing clothes and ultrasound was conducted while the participants were sitting on a chair without armrests. The supraspinatus, infraspinatus, subscapularis, teres minor, and biceps brachii muscles were examined with participants in the modified Crass position. The subacromial-subdeltoid bursa and acromioclavicular joint were also examined. The most common cause of shoulder injury in golfers, including rotator cuff tears, is known to be impingement syndrome [4]. Thus, abnormal ultrasonographic findings were used to divide participants into a rotator cuff muscle tear group and a non-rotator cuff tear group. The rotator cuff muscle tear group was further divided into a supraspinatus muscle tear (the most common injury after shoulder impingement syndrome) group and a non- 
supraspinatus muscle tear group.

Statistical analysis was performed using SPSS ver. 18.0 (SPSS Inc., Chicago, IL, USA) and the statistical significance level was set at $\mathrm{p}<0.05$. To assess the correlations between the participants' general characteristics and abnormal ultrasonographic findings, chi-square and Fisher exact tests were used. Other factors, such as specific location of shoulder pain and abnormal ultrasonographic findings, other upper-extremity pain, and history of medical visits, were also assessed using chi-square and Fisher exact tests.

\section{RESULTS}

\section{General characteristics and clinical features of study subjects}

There were 68 male and 9 female participants. The average age of the participants was $48.5 \pm 6.9$ years, and the average amount of golfing experience was $2.9 \pm 0.9$ years. The average number of golf practices per week was $2.8 \pm 1.0$ times, and the average time spent practicing golf per week was $3.9 \pm 1.7$ hours. Fifty participants reported additional upper limb pain, and 33 participants reported that they had previously visited clinics because of golfrelated shoulder pain (Table 1). The surveys reported that 73 participants had right swings, whereas only 4 participants had left swings. Sixteen participants presented with pain in the dominant shoulder, while 51 participants pre-

Table 1. General characteristics of study subjects $(n=77)$

\begin{tabular}{|lc|}
\hline \multicolumn{1}{c}{ Characteristic } & Value \\
\hline Age (yr) & $48.5 \pm 6.9$ \\
\hline Sex (male:female) & $68: 9$ \\
\hline Height (cm) & $167.8 \pm 8.1$ \\
\hline Weight (kg) & $73.2 \pm 10.2$ \\
\hline Golf career (yr) & $2.9 \pm 0.9$ \\
\hline Practice day per week & $2.8 \pm 1.0$ \\
\hline Practice hour per week & $3.9 \pm 1.7$ \\
\hline Other upper-extremity pain & $50(64.9)$ \\
\hline History of clinic visit & $33(42.9)$ \\
\hline Most painful swing phases & \\
\hline Address \& back swing & $24(31.1)$ \\
\hline Forward swing \& impact & $39(50.6)$ \\
\hline Follow-through & $14(18.3)$ \\
\hline
\end{tabular}

Values are presented as mean \pm standard deviation or number (\%). sented with pain in the non-dominant shoulder and 10 participants complained of pain in both shoulders. According to the surveys, the most painful swing phase was forward swing and impact in 39 participants, followed by address and back swing in 24 participants and followthrough in 14 participants (Table 2).

\section{Ultrasonographic findings}

Ultrasound examinations revealed that rotator cuff tears were present in 60 individuals, of whom 12 presented with damage to the dominant shoulder and 48 presented with damage to the non-dominant shoulder. Seven cases showed no abnormal ultrasonographic findings of the rotator cuff muscles. Rotator cuff tears can be largely classified into supraspinatus muscle tears and non-supraspinatus muscle tears. Among the findings in the supraspinatus tear group, supraspinatus partial thickness tear of the dominant shoulder and supraspinatus partial thickness tear of the non-dominant shoulder were the most frequent injuries, accounting for 5 and 12 cases, respectively. Supraspinatus full thickness tear of the non-dominant shoulder was only observed in cases with isolated supraspinatus tears. Cases with findings in the supraspinatus and other rotator cuff muscles only presented with partial thickness tears. In the nonsupraspinatus tear group, subscapularis partial thickness tears of the dominant shoulder and subscapularis partial thickness tears of the non-dominant shoulder were the most frequent injuries, accounting for 2 and 7 cases, respectively. A subscapularis full thickness tear was observed in only 1 case (Table 3 ).

Subacromial-subdeltoid bursitis, acromioclavicular osteoarthritis, and biceps tenosynovitis were additional findings that accompanied shoulder injuries. Subacromial-subdeltoid bursitis was observed in cases with supraspinatus damage in both the dominant and the non-

Table 2. Swing direction and location of shoulder pain in the study subjects

\begin{tabular}{lccc}
\hline \multirow{2}{*}{$\begin{array}{c}\text { Location } \\
\text { of pain }\end{array}$} & \multicolumn{3}{c}{ Swing direction } \\
\cline { 2 - 4 } & Right & Left & Total \\
\hline Right shoulder & $16(20.8)$ & $4(5.2)$ & $20(26.0)$ \\
Left shoulder & $47(61.0)$ & $0(0)$ & $47(61.0)$ \\
\hline Both shoulders & $10(13.0)$ & $0(0)$ & $10(13.0)$ \\
\hline Total & $73(94.8)$ & $4(5.2)$ & $77(100)$ \\
\hline
\end{tabular}

Values are presented as number (\%). 
dominant shoulders. Acromioclavicular osteoarthritis was observed in 4 cases in the supraspinatus tear group and 2 cases in the non-supraspinatus tear group, and was the only finding in 1 dominant shoulder case and 2 nondominant shoulder cases. Biceps tenosynovitis was observed in 3 non-dominant shoulder cases. Two of those were in the supraspinatus tear group and 1 was in the non-supraspinatus tear group (Table 4).

\section{Analysis of ultrasonographic findings and clinical features}

The participants' ages, golf experience, average number of golf practices per week, and average time spent practicing golf per week were investigated to uncover correlations with abnormal ultrasonographic findings. The results indicated that there were no correlations between abnormal ultrasonographic findings and age, golf experience, or average number of golf practices per week.
Only an average golf practice time per week of over 4 hours showed a significant correlation with the incidence of supraspinatus muscle tear (Table 5). Analysis of both shoulders showed that golf-related shoulder pain and abnormal ultrasonographic findings were significantly more likely to be found in the non-dominant shoulder. Investigation of the correlation between abnormal ultrasonographic findings and the most painful swing phases revealed that there were no correlations with any swing phase.

The group with no previous visits to clinics had a significantly higher number of abnormal ultrasonographic findings, whereas a significant proportion of the group that had previously visited clinics showed no ultrasonographic abnormalities. No significant differences in the number of ultrasonographic findings were observed between the group with additional upper limb pain and the group without additional upper limb pain.

Table 3. Abnormal ultrasonographic findings in rotator cuff muscles

\begin{tabular}{|lcc|}
\hline \multicolumn{1}{|c|}{ Type of RCT } & $\begin{array}{c}\text { Dominant } \\
\text { shoulder }\end{array}$ & $\begin{array}{c}\text { Non-dominant } \\
\text { shoulder }\end{array}$ \\
\hline Supraspinatus tear group & & \\
\hline Supraspinatus PTT only & 5 & 12 \\
\hline Supraspinatus FTT only & 0 & 6 \\
\hline Supraspinatus PTT+subscapularis PTT & 2 & 4 \\
\hline Supraspinatus PTT+infraspinatus PTT & 1 & 6 \\
\hline Supraspinatus PTT+infraspinatus PTT+subscapularis PTT & 2 & 7 \\
\hline Non-supraspinatus tear group & & 1 \\
\hline Subscapularis PTT only & 2 & 1 \\
\hline Subscapularis FTT only & 0 & 2 \\
\hline Infraspinatus FTT only & 0 & \\
\hline Subscapularis PTT+infarspinatus PTT & 0 & \\
\hline
\end{tabular}

RCT, rotator cuff tear; PTT, partial thickness tear; FTT, full thickness tear.

Table 4. Combined abnormal ultrasonographic findings

\begin{tabular}{|c|c|c|c|c|c|c|c|c|c|c|c|}
\hline \multirow{3}{*}{ Combined finding } & \multicolumn{5}{|c|}{ Dominant shoulder } & \multicolumn{5}{|c|}{ Non-dominant shoulder } & \multirow{3}{*}{ Total } \\
\hline & \multicolumn{2}{|c|}{ SsT } & \multicolumn{2}{|c|}{ N-SsT } & \multirow{2}{*}{ Isolated } & \multicolumn{2}{|c|}{ SsT } & \multicolumn{2}{|c|}{ N-SsT } & \multirow{2}{*}{ Isolated } & \\
\hline & PTT & FTT & PTT & FTT & & PTT & FTT & PTT & FTT & & \\
\hline $\begin{array}{l}\text { Subacromial-subdeltoid } \\
\text { bursitis }\end{array}$ & 5 & 0 & 0 & 0 & 0 & 15 & 6 & 0 & 0 & 0 & 26 \\
\hline $\begin{array}{l}\text { Acromioclavicular } \\
\text { osteoarthritis }\end{array}$ & 1 & 0 & 1 & 0 & 1 & 2 & 1 & 1 & 0 & 2 & 9 \\
\hline Biceps tenosynovitis & 0 & 0 & 0 & 0 & 0 & 1 & 1 & 1 & 0 & 0 & 3 \\
\hline
\end{tabular}

SsT, supraspinatus tear group; N-SsT, non-supraspinatus tear group; PTT, partial thickness tear; FTT, full thickness tear. 
Table 5. Analysis of clinical features and abnormal ultrasonographic findings

\begin{tabular}{|c|c|c|c|}
\hline & $\begin{array}{l}\text { Supraspinatus } \\
\text { tear group }\end{array}$ & $\begin{array}{c}\text { Non- } \\
\text { supraspinatus } \\
\text { tear group }\end{array}$ & $\begin{array}{l}\text { No rotator } \\
\text { cuff tear } \\
\text { group }\end{array}$ \\
\hline \multicolumn{4}{|l|}{ Age (yr) } \\
\hline$<40$ & 16 & 4 & 2 \\
\hline $40-50$ & 20 & 5 & 3 \\
\hline $50-60$ & 21 & 4 & 2 \\
\hline \multicolumn{4}{|c|}{ Golf career (yr) } \\
\hline$<1$ & 8 & 1 & 2 \\
\hline $1-3$ & 15 & 3 & 4 \\
\hline$\geq 3$ & 24 & 9 & 1 \\
\hline \multicolumn{4}{|c|}{ Practice day per week } \\
\hline$<2$ & 5 & 2 & 3 \\
\hline $2-3$ & 21 & 5 & 3 \\
\hline$\geq 3$ & 23 & 6 & 1 \\
\hline \multicolumn{4}{|c|}{ Practice hour per week } \\
\hline$<2$ & 4 & 1 & 2 \\
\hline $2-4$ & 12 & 2 & 3 \\
\hline$\geq 4$ & $31^{*}$ & 10 & 2 \\
\hline
\end{tabular}

${ }^{*} \mathrm{p}<0.05$ ( $\chi^{2}$ and Fisher exact tests).

\section{DISCUSSION}

With the increase in the population of golfers, interest in golf-related injuries is also increasing. Golf-related injuries are usually caused by insufficient warm-up, excessive nervousness, and lack of concentration [9]. Injuries in amateur golfers are usually caused by a lack of skills, whereas injuries in experts are mostly caused by overuse of muscles [10]. Although the prevalence of golf-related shoulder injuries is not high, their onset can greatly affect a golfer's performance.

Owing to the large proportion of right-handed persons in the general population, $94.8 \%$ of the participants had a right swing direction. In participants with a right swing direction, the right shoulder was considered the dominant shoulder and the left shoulder was considered the non-dominant shoulder. Previous studies [11] reported that non-dominant shoulders, which lead the swing, are at a relatively higher risk of injury during a radical swing. It has also been reported $[12,13]$ that golf-related shoulder pain occurs mostly in the non-dominant shoulder. The results of the present study also suggest that the pro- portion of participants with pain in the non-dominant shoulder was significantly higher than the proportion of those with pain in the dominant shoulder. In addition, the frequency of abnormal ultrasonographic findings was significantly higher in the non-dominant shoulder. However, 5 of the 67 cases with abnormal ultrasonographic findings $(7.5 \%)$ presented with no shoulder pain, which indicates that ultrasonographic confirmation is necessary even when no pain is present.

Of the total of 67 cases, abnormal ultrasonographic findings indicated that rotator cuff tear was present in 60 cases. Supraspinatus muscle tear was especially prevalent, accounting for 47 cases. Rotator cuff tear usually occurs when the supraspinatus muscle moves below the acromion and causes impingement. Small tears in the supraspinatus muscle extend from the anterior distal joint to the entire supraspinatus and expand to other rotator cuff muscles, including the infraspinatus [14]. Impingement caused by shoulder overuse is the major cause of supraspinatus muscle tear. Impingement-prone conditions are produced when an overhead motion is forced in the dominant shoulder during address and back swing and in the non-dominant shoulder during follow-through. Small tears are produced with repetition of rapid swings, which then progress to supraspinatus muscle tears. Supraspinatus muscle full thickness tears were observed only in cases with isolated supraspinatus findings in the non-dominant shoulder. It can be inferred that supraspinatus full thickness tears were produced by the golfers' radical swing movements during followthrough.

Thirteen cases presented with no supraspinatus muscle tears. Subscapularis muscle tear was the most prevalent of these injuries, and full thickness tears were also observed. The subscapularis muscle is usually the most active rotator cuff muscle during golf swings [13]. The subscapularis muscle is known to produce a concentric force on the dominant shoulder during down swing and an eccentric force on the non-dominant shoulder during follow-through, which are important for swing breaking [14]. Therefore, excessive swing movement and the shock caused by the contact of the club with the ground during down swing and follow-through could cause damage to the subscapularis muscle. Infraspinatus full thickness tears and a combination of subscapularis and infraspinatus partial thickness tears were also observed in some 
cases. These injuries could have been caused by trauma without excessive use of the rotator cuff. Very few studies have been conducted on whether muscle overuse or trauma is a major cause of golf-related injuries. It has been reported [15] that overuse accounts for $54.5 \%$ of injuries, whereas trauma accounts for $45.5 \%$ of injuries. Thus, the likelihood that many injuries are caused by trauma cannot be disregarded.

According to our findings, subacromial-subdeltoid bursitis, acromioclavicular osteoarthritis, and biceps tenosynovitis are observed as accompanying findings in patients with rotator cuff tears. Subacromial-subdeltoid bursitis was only observed in cases with supraspinatus muscle tears. This result indicates that the cause of subacromial-subdeltoid bursitis could also be repetitive overuse and could be a secondary effect of impingement. Acromioclavicular osteoarthritis was the sole finding in 3 cases without rotator cuff tears. Similar to subscapularis and infraspinatus tear, acromioclavicular osteoarthritis may be caused by trauma. Biceps tenosynovitis was observed in 2 cases in the group with supraspinatus tears in the non-dominant shoulder and 1 case in the group without supraspinatus tears in the non-dominant shoulder. It can be deduced that biceps tenosynovitis is caused by excessive flexion of the non-dominant elbow during follow-through.

A study [15] that investigated golf-related habits between amateur golfers with and without golf-related injuries reported that, although there were no differences in age and length of golfing experience, the injured group underwent more golf rounds or practices per week. In addition, the injured group experienced more fatigue after a golf round or practice session. In this study, there was no control group composed of uninjured amateur golfers. Therefore, an accurate comparison was not possible. The results of this study, which was confined to injured participants, showed that age, golf experience, and number of golf practices per week were not correlated with shoulder injuries. However, participants who spent on average 4 hours or more per week practicing golf showed a significant association with the supraspinatus muscle tear group, which concurs with the results of previous studies [15]. Taking into account that supraspinatus tears are usually caused by repetitive muscle overuse, the amount of time spent practicing golf could reasonably be a more influential factor in shoulder injuries than the number of golf practice sessions.

Each golfer's personal preferences and habits cause force exertions on different body parts during the swing. Therefore, the location of pain and painful swing phases are different in each golfer. The muscles that are responsible for each swing phase have been identified in previous studies. The locations of injuries and abnormal findings are different in each swing phase [15]. However, the results of this study showed no characteristic abnormal ultrasonographic findings related to address and back swing, forward swing and impact, or follow-through. These results may be attributable to the method of evaluation of pain in different swings, which was only done through subjective surveys and did not involve meticulous clinical evaluations such as motion analysis. Accordingly, a future study using meticulous evaluation tools such as motion analyzers is necessary.

No abnormal ultrasonographic findings were observed in 20 of 87 cases $(23.0 \%)$, even though these participants complained of pain. The pain in these cases could have been localized to the soft tissues of the trapezius and the levator scapulae [16], or caused by shoulder instability, such as from damage due to a superior labral tear from the anterior to the posterior direction [17]; however, such damage is uncommon. Further examinations would be necessary to confirm such cases.

No differences were observed in the proportion of rotator cuff tears between the group with additional upper limb pain in the elbow or the wrist and the group without additional upper limb pain. Rotator cuff tears probably occur independently of other upper limb injuries. However, the fact that 50 participants $(64.9 \%)$ had additional upper limb pain indicates that the possibility of additional upper limb injuries should be considered in patients with golf-related shoulder pain. The group with a history of clinic visits had a relatively low proportion of abnormal ultrasonographic findings. It can be concluded that early treatment of golf-related shoulder injuries may delay aggravation and progression of damage. A previous study [18] reported that $39 \%$ of the participants had previously been treated for golf-related shoulder pain at healthcare institutions. Only $41.6 \%$ of the participants in this study reported a history of clinic visits owing to golf-related injuries, which may indicate that golfers are not aware that golf-related injuries require clinic visits. Therefore, healthcare visits at the time of onset of shoulder pain 
should be promoted among golfers.

This study has some limitations. First, it was conducted without a control group composed of amateur golfers without shoulder pain. Second, although the participants were divided according to sex before the investigation, the small number of female participants did not allow for a statistical comparison between the sexes. Third, although ultrasonographic examination is a very accurate screening tool, lack of other imaging techniques such as arthrography did not allow confirmation of the findings. Fourth, golf-related factors such as type of golf lesson, accuracy, instructor level, and time of lesson were not addressed. Lastly, the small number of participants does not reflect the entirety of the amateur golfer population and the recruitment notice may have only attracted participants with severe shoulder pain. The limitations described above should be addressed in future largescale studies to accurately determine the characteristics of golf-related shoulder injuries.

Golf is a non-contact sport that involves striking an immobile ball with a club. Compared with other sports, golf is a low-intensity activity; therefore, golf-related injuries and their prevention are often neglected. However, golfers are at a moderate risk for injuries [19] and the number of golf-related injuries, including shoulder injuries, is expected to increase with the increasing number of amateur golfers. The results of this study revealed that golf-related shoulder injuries most frequently occur in the non-dominant shoulder and multiple abnormal findings are usually observed. The supraspinatus muscle was much more frequently damaged than were other muscles. A correlation was observed between the duration of golf practice and supraspinatus tears. On the basis of these results, patients evaluated for golf-related shoulder pain should be advised on the appropriate amount of golf practice and should undergo ultrasonographic evaluation.

\section{CONFLICT OF INTEREST}

No potential conflict of interest relevant to this article was reported.

\section{REFERENCES}

1. Murase Y, Kamei S, Hoshikawa T. Heart rate and metabolic responses to participation in golf. J Sports Med Phys Fitness 1989;29:269-72.

2. Batt ME. A survey of golf injuries in amateur golfers. Br J Sports Med 1992;26:63-5.

3. McCarroll JR, Rettig AC, Shelbourne KD. Injuries in the amateur golfer. Phys Sportsmed 1990;18:122-6.

4. Morrison DS, Greenbaum BS, Einhorn A. Shoulder impingement. Orthop Clin North Am 2000;31:285-93.

5. Jobe FW, Moynes DR, Antonelli DJ. Rotator cuff function during a golf swing. Am J Sports Med 1986;14:38892.

6. Murrell GA, Walton JR. Diagnosis of rotator cuff tears. Lancet 2001;357:769-70.

7. Kim KC, Rhee KJ, Shin HD, Byun KY. physical examinations of rotator cuff tear. J Korean Shoulder Elbow Soc 2008;11:13-8.

8. Maffulli N, Regine R, Carrillo F, Capasso G, Minelli S. Tennis elbow: an ultrasonographic study in tennis players. Br J Sports Med 1990;24:151-5.

9. Lee SI, Park BS. A study of golf injuries based on the comparison of professional and amateur golfers. Korea Sport Res 2005;16:797-804.

10. Theriault G, Lachance P. Golf injuries: an overview. Sports Med 1998;26:43-57.

11. Park TS. Injuries of the upper extremity in golf. J Korean Orthop Soc Sports Med 2004;3:10-4.

12. Jobe FW, Pink MM. Shoulder pain in golf. Clin Sports Med 1996;15:55-63.

13. Jobe FW, Bradley JP. The diagnosis and nonoperative treatment of shoulder injuries in athletes. Clin Sports Med 1989;8:419-38.

14. Pink M, Jobe FW, Perry J. Electromyographic analysis of the shoulder during the golf swing. Am J Sports Med 1990;18:137-40.

15. Thériault G, Lacoste E, Gaboury M. Golf injury characteristics: a survey form 528 golfers. Med Sci Sports Exerc 1996;28:65-71.

16. Lim KB, Lee HJ, Joo SJ, Cho YJ, Chai JW. The findings of physical examination and ultrasonography at the shoulders in high school baseball players. J Korean Acad Rehabil Med 2005;29:81-6.

17. Moon YL, Kim DH, Jang KS, Lee KI. Acute rotator cuff tear in middle-aged amateur golfer: a case report. J 
Korean Orthop Soc Sports Med 2007;6:119-20.

18. Kim DK, Seo KM, Shin JY. Analysis of questions on golf related pain on the internet. J Korean Acad Reha- bil Med 2002;26:776-80.

19. McCarroll JR. The frequency of golf injuries. Clin Sports Med 1996;15:1-7. 